\title{
SWARM ROBOT FOR IRRIGATION BASED APPLICATION
}

\author{
Sk. Bilal,V.Meghanethra, Sk.Fareed \\ Department of Electronics and Communication Engineering \\ SRM Institute Of Science And Technology, Kattankulathur \\ SRM Institute Of Science And Technology, India
}

\begin{abstract}
The concept of smart agriculture is developing, as the sensors can give information in regards to the territories of their development. The function of this project is to gauge the humidity level of soils in crops through sensors. The humidity level measured is given to Arduino and as indicated by which water siphons are worked. In this technique, we are also implementing swarm concept which consists of a master and a slave robot. The master robot will be stationary and slave robot will perform the task given to it by the master robot. The instructions are given from an android application to master and the master will give it to slave and it moves accordingly. The main advantage of this swarm concept is we can control the robot from a certain distance and use it to water the plants by measuring their humidity levels.
\end{abstract}

\section{INTRODUCTION}

The swarm robot means "Group of Robots".Swarm robotics is another methodology for the coordination of multi-robot frameworks that comprises of enoromous number of physical robots. This concept is developed by observing the artifificial swarm intelligence, as well as organic investigation of bugs, ants and different fifields in nature, where swarm conduct occurs. Swarm robot comprises of master and slave robots. In swarm robot there can be one or more master or slave robots. By utilizing this idea we can broaden the communication region by utilizing Zigbee module. The fundamental goal of this project is to build up a correspondence among master and slave robot utilizing Zigbee and perform task allocated to slave robot.

Here in this project, we are going to combine swarm robotics concept as well as a plant watering system to the slave robot which waters the plants by checking the humidity level of the soil using a soil moisture sensor. if the amount of water is below 30 percent in the soil it means dry soil then automatically water is poured over and if there is a plant having moisture up to 50 percent then the robot will not provide water to the plant. In this project the slave robot is controlled using android application from smart phone. The reason for this project is to give the adequate water the plant is required and to utilize water effectively.

\section{WORKING}

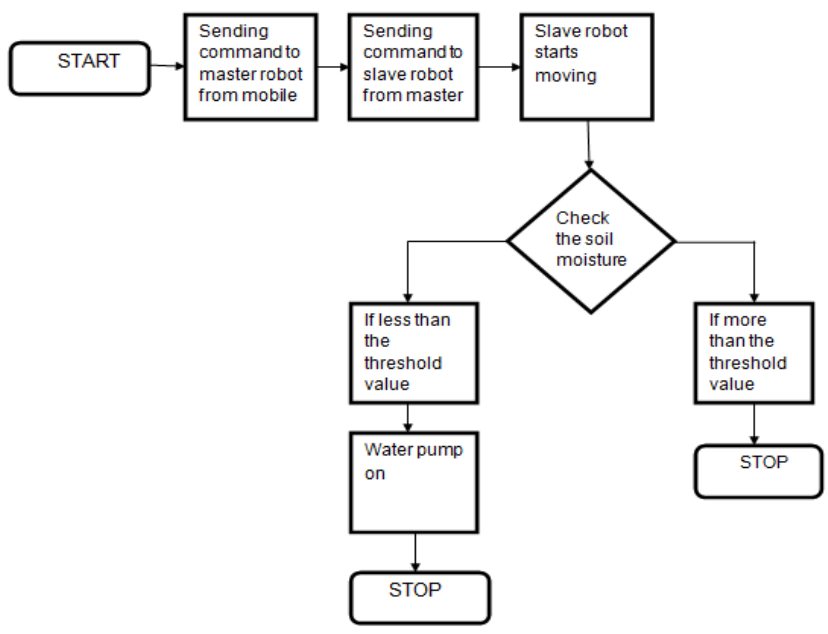

Fig.1.Flow Chart

1) The working of this project follows the following steps. First the commands to the master robot from smart phone through an application, where the smart phone is connected via bluetooth module to the master robot.

2) Then the commands recieved by the master robot is sent to the slave robot through Zigbee module.

3) The slave robot will follow according to the commands given to it and starts moving

4) It will go near a plant and checks the humidity level of the plant using a soil moisture sensor which is connected to the slave robot.

5) If the humidity level of soil is below the threshold value, then the water motor pump will be turned on and water is poured over the plant.

6) If it is exceeding the threshold value, then it will stop. 


\section{SYSTEM DESIGN}

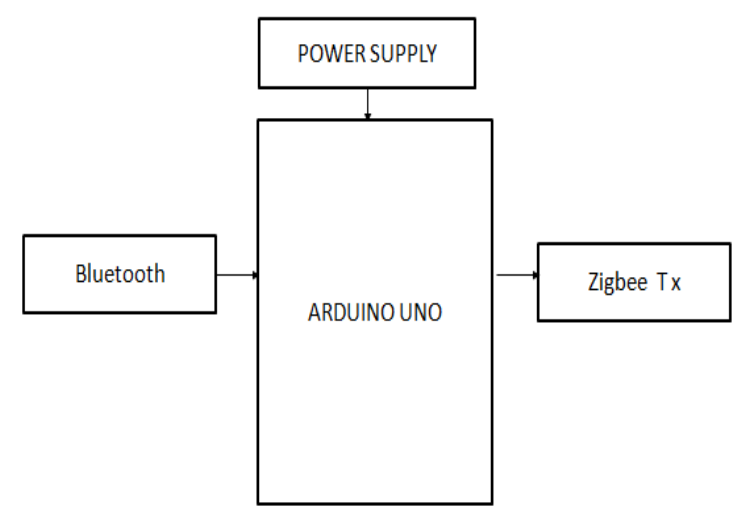

Fig.2.Block Diagram of Master Robot

The master robot consists of a Bluetooth module(Hc-05/06), a Zigbee transmitter and an Arduino Uno board. The power supply to the master robot can be given from a $5 \mathrm{~V}$ adapter or from a laptop by using an arduino cable connector.

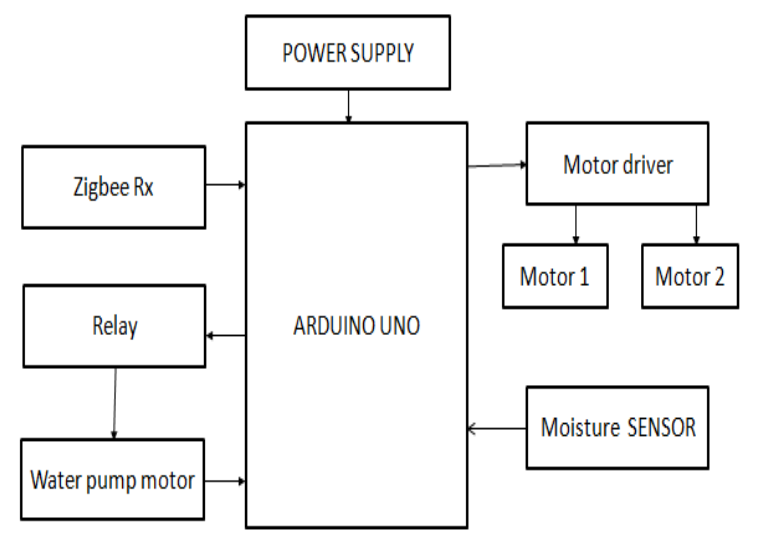

Fig.3. Block diagram of Slave Robot

The slave robot consists of an Arduino Uno board, Zigbee reciever, Motor driver, two motors, a relay, a water pump motor, $12 \mathrm{v}$ battery and a soil moisture sensor. The slave robot recieves instructions from master robot through zigbee and it follows the instructions recieved. This robot is utilized to quantify the humidity level of soil and to water the plants.

\section{EXISTED METHOD}

The Normally available methods for irrigation are sprinkler and drip irrigation. The sprinkler system sprinkles the water into air and breaks water into droplets like a rain. The drip irrigation system directly gives the water to the root by pipelines connected under the plants, this method is effective than sprinkler. These systems are effective but less efficient, it will not stop after the plant got required amount of water and often there is loss of water.

\section{PROPOSED METHOD}

In our proposed work, we focus on developing a self-suffificient water system work and set up a savvy answer for irrigation problem of developing countries by using the master and slave concept from swarm robotics. This system checks the humidity level of soil by a sensor and gives the water according to it. Here the system is controlled from a smart phone through an android application.

\section{EMBEDDED SYSTEM}

Arduino: Arduino Uno is a type of microcontroller which is supported by ATmega328P(datasheet). It has total 28 pins of which 14 are used as input/output pins (sometimes 6 pins are used as PWM outputs), 6 are used as analog inputs, it has a $16 \mathrm{MHz}$ quartz, a USB interface, an powerful socket, an ICSP header and a reset button. In this project, we use aeduino uno with VGA portto interact with the zigbee board. To make the board run one can connect it with a device which has USB Port or to a battery.

ZigBee: Zigbee is a high level specifification for the usage of lightweight low power wireless radio networks based on IEEE standard 802.15.4-2003. Zigbee is for devices that are not needed for data transmission at a higher rate, that need easy wireless networking. The Zigbee interface platform is intended to be easier and cheaper than most WPAN, like Bluetooth or more general wireless communication such as Wi-Fi. Wireless illumination switches, house energy control, traffific management and other home and industrial products that include short-range low-speed wireless data transfer include applications.

Soil Moisture sensor: The Sensor uses a dielectric permittivity measuring device. Dielectric permittivity in the soil is water dependent. The sensor tests the water level across the whole duration of the instrument. It is made of two probes used for volumetric water quality measurements. The two probes cause the current to flflow through the ground and then the resistance value is determined. The module also includes a potentiometer which sets the threshold value and compares the threshold value to the LM393 comparator. If there is more water the resistance will be less, if there is less water the resistivity will be higher.

Blutooth Module: The bluetooth module used in this project is a HC-05 / 06 module which is perfectly suitable for swarm robot concept. The HC-05 bluetooth module has a Master and Slave confifiguration. The specififications of this bluetooth are, it has protocol of bluetooth V 2.0+EDR, it works with the power supply of $3.3 \mathrm{~V}-5 \mathrm{~V}$ DC $50 \mathrm{~mA}$, it has frequency upto $2.4 \mathrm{GHz}$ of ISM band, it has GFSK modulation, it has sensitivity less than equal to $-84 \mathrm{dBm}$ at 0.1 percent of $\mathrm{BER}$, it can work 


\section{International Journal of Engineering Applied Sciences and Technology, 2020 \\ Vol. 5, Issue 6, ISSN No. 2455-2143, Pages 331-334 \\ Published Online October 2020 in IJEAST (http://www.ijeast.com)}

at tempereature from -20 to +75 centigrade. This module has a CSR bluecore 04-external single chip with CMOS system and AFH feature.

\section{RESULT}

Sending instructions to master:

Here the instructions are given to the master from smart phone by connecting through bluetooth and the control is given from android application available in playstore.

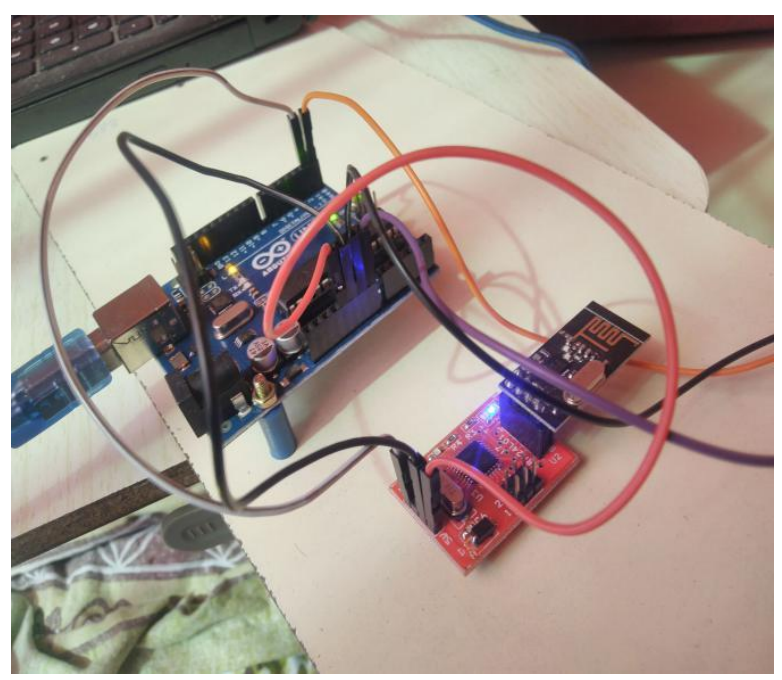

Fig.4.Master Robot

\section{Instructions recieved by slave:}

Here the instruction given to master is send to slave by zigbee transmitter in master and is recieved by zigbee reciever in slave and it starts moving accordingly. It goes near a plant and soil sensor is put into soil and soil moisture is measured and it gives water.

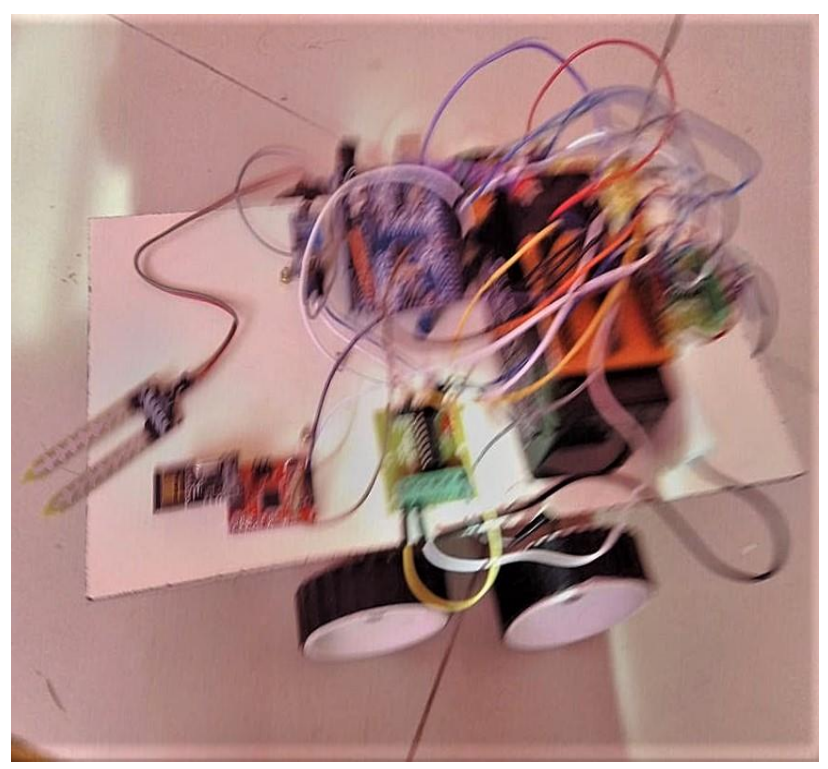

Fig.5.Slave Robot

\section{CONCLUSION}

The swarm robot for irrigation based application is based on the swarm robotics concept with a plant watering system added to the slave robot. Controlling of the slave robot is done from an android application through a smart phone which is connected to the master robot through a bluetooth module. Whatever the instructions given to the master are sent to the slave by a zigbee transreciever module. The slave robots task is to perform humidity level check of soil and to water the plants, for that a soil moisture sensor is placed on slave robot. If the humidity level is lower than the threshold value the slave robot will waters the plant automatically and it waters only suffificient water to the plant not more or less. Thus, there will be no wastage of water and not more people required to do this job and we can operate this robot from a distance. The arduino software used in this method is very effificient and produced correct output.

\section{REFERENCES}

1. Albani, D., IJsselmuiden, J., Haken, R., and Trianni, V. (2017). "Monitoring and mapping with robot swarms for agriculturalapplications." 2017 14th IEEE International Conference on Advanced Video and Signal Based Surveillance (AVSS), IEEE. 1-6.

2. Carbone, C., Garibaldi, O., and Kurt, Z. (2018). "Swarm robotics as a solution to crops inspection for precision agriculture." KnE Engineering, 552-562.

3. Hasan, Y. (2017). "Swarm robots and their applications." Journal of Computer Engineering, 19(1), 46-47.

4. Rafifi, R. H., Das, S., Ahmed, N., Hossain, I.,andReza,S.T.(2016). "Design\&implementation of a line following robot for irrigation based application." 2016 19th International Conference on Computer and Information Technology (ICCIT), IEEE. 480-483.

5. J.Senthil Kumar, E.Sweetline Sylvia, C.Srijayasri, G.Sharmila.(2017)Task Coordination and Control between Swarm of Robots for assisting Farmers. International Journal of Advanced Research in Electronics and Communication Engineering (IJARECE) Volume 6, Issue 3, March 2017.

6. Devdutt , Ishlok Vashistha , Vimlesh Singh , Priyanka Bansal, Abhiruchi Passi.(2017)PLANT

WATERING ROBOT “PLANT O BOT”.IJCSMC, Vol.6, Issue.4, April 2017.

7. Shamshiri, R. R., Weltzien, C., Hameed, I. A., Yule, I . J., Grift, T. E., \& Balasundram, S. K. (2018). Research and development in agricultural robotics: A perspective of digital farming. Int J Agric \& Biol Eng, 11(4), 1-14.

8. Ju, C., \& Son, H. I. (2019). A distributed swarm control for an agricultural multiple unmanned aerial vehicle system. Proceedings of the Institution of 


\section{International Journal of Engineering Applied Sciences and Technology, 2020 Vol. 5, Issue 6, ISSN No. 2455-2143, Pages 331-334 \\ Published Online October 2020 in IJEAST (http://www.ijeast.com)}

Mechanical Engineers, Part I: Journal of Systems and Control Engineering, 233(10), 1298-1308.

9. Khaluf, Y., Vanhee, S., \& Simoens, P. (2019). Local ant system for allocating robot swarms to time-constrained tasks. Journal of Computational Science, 31, 33-44.

10. Trianni, V., IJsselmuiden, J., \& Haken, R. (2016). The Saga Concept: Swarm Robotics for Agricultural Applications. Technical Report. 2016. Available online: http://laral. istc. cnr. it/saga/wp-content/uploads/2016/09/sagadars2016. pdf (accessed on 23 August 2018).

11. Tan, Y. (2013). Swarm robotics: collective behavior inspired by nature. J Comput Sci Syst Biol, 6, e106.

12. Rafael, P., \& Heitor, S. L. (2012). Theory and New Applications of Swarm Intelligence. InTech. Janeza Trdine, 9, 51000.

\section{ACKNOWLEDGEMENT}

We would like to express our deepest gratitude to our guide, Dr.S.Yuvaraj (Asst.Professor, Department of Electronics and Communication, SRM Institute of Science and Technology, Kattankulathur campus, Chennai) his valuable guidance, consistent encouragement, personal caring, timely help and providing us with an excellent atmosphere for doing research. All throught the work, in spite of his busy schedule, he has extended cheerful and cordial support to us for completing this research work. 